\title{
Scour at offshore structures
}

\section{RJS Whitehouse, JM Harris, TR Mundon and J Sutherland}

HR Wallingford, Howbery Park, Wallingford, Oxfordshire OX10 8BA, UK. r.whitehouse@hrwallingford.co.uk, j.harris@hrwallingford.co.uk, i.sutherland@hrwallingford.co.uk

Keynote Paper presented by Dr Richard Whitehouse at ICSE-5, Tuesday, November 9, 2010

Published in Proceedings of the Fifth International Conference on Scour and Erosion (ICSE-5), American Society of Civil Engineers, San Francisco, California, 7-11 November, 2010

\section{Abstract}

The drive for marine offshore renewables developments has led to focussed requirements for scour hazard assessment relating to foundations and the cabling necessary for in-field transmission and power export. Foundations can represent a significant proportion of the installed capital costs of a renewable energy device so the offshore renewable energy community can benefit from the sharing of information and the development of common approaches to scour and geotechnical issues. Foundation options including monopiles, multi-piled tripods and jackets, gravity bases, or suction piles are being considered for a variety of offshore renewable installations. This paper concentrates on scour assessment challenges in currents and waves, including scour experience at built foundations, time-series predictions of scour and considerations with respect to the evaluation of heterogeneous soils.

\section{Introduction}

In January 2007, the European Commission published a Renewable Energy Roadmap outlining a long-term strategy that called for a mandatory target of a $20 \%$ share of renewable energies in the European Union's (EU) energy mix by 2020. The target was endorsed by EU leaders in March 2007. To achieve this objective, the EU adopted a new Renewables Directive in April 2009, which set individual targets for each member state. There are a number of technologies that are classed as renewable including wind, hydro-power, tidal and wave.

To date within the United Kingdom (UK) a number of demonstrator projects have been constructed covering wind, wave and tidal generation. However, only offshore wind has been developed at large-scale at present as part of two rounds of commercial development of offshore wind farms (OWFs). In June 2008, The Crown Estate - responsible for licensing seabed use - announced proposals for a third round of offshore wind farms to develop an additional $25 \mathrm{GW}$ of energy to the $8 \mathrm{GW}$ already planned for under Rounds 1 and 2 . The size of these Round 3 developments will vary, but the largest of these zones will involve the construction of around 2500 seabed foundation structures.

Under Round 1 and 2 developments only monopile foundations have been used, primarily due to cost and being tried technology, although several other European (non UK) wind farms have been built using gravity base foundations. Byrne and Houlsby (2003) state that "in contrast to typical oil and gas structures used offshore, for a wind turbine the foundations may account for up to $35 \%$ of the installed cost". Therefore, one 
of the future challenges for large volume installation of offshore wind is the control and minimisation of these costs.

For tidal energy devices one of the principal requirements for many of the devices proposed is their placement in areas of strong tidal energy, and this has implications not only for the stability of the foundation option, but also for the construction methodology.

Similarly wave energy devices are designed to be located in shallow, coastal environments as either floating or bottom mounted systems. These devices, by design, are intended to be located in environments with strong wave action. This may be substantial during storm events, which has implications for the integrity of the anchoring system keeping the wave device on station or the design of the device if it is seabed mounted.

This paper explores some of the challenges facing the offshore renewable industry in respect of the foundation designs and specifically the requirements for scour hazard assessment using the combined experience from those developments currently operational or under construction.

\section{Preliminary assessment of scour hazard}

At its simplest, an assessment of the scour risk at any given site can be based on observing natural features in the seabed environment that indicate the sediment has been mobile in the case of sands, or eroded, in the case of clays (Table 1). This assessment does not provide any information about when the seabed soil was mobilised but it does indicate whether the site is likely to experience soil mobility. In this situation, where the soil is mobile under the prevailing environmental conditions, the installation of a structure on the seabed can induce scouring.

Table 1: Examples of seabed features indicating mobility or erosion

\begin{tabular}{l|l}
$\begin{array}{l}\text { Sand - indicators of mobility } \\
\text { Ripple marks }\end{array}$ & $\begin{array}{l}\text { Clay - indicators of erosion } \\
\text { Megaripples }\end{array}$ \\
$\begin{array}{l}\text { Sandwaves } \\
\text { Obstacle marks - scour and deposition around } \\
\text { rocks or other debris on the seafloor }\end{array}$ & $\begin{array}{l}\text { Obstacle marks - scour around rocks or other } \\
\text { debris on the seafloor }\end{array}$ \\
\hline
\end{tabular}

It may also be necessary to consider bed changes due to the movement of sandbanks, sandwaves, ridges and channels. These changes, which can be progressive, seasonal, or caused by extreme events, lead to variations in seabed level and composition of the soil.

The next level of assessment combines the known characteristics of the hydrodynamic conditions (wave and currents) with knowledge of the soil to make an assessment of the soil mobility status (Whitehouse, 2006). This leads to an understanding under what conditions the soil is mobile and feeds directly into the scour assessment methodology. Therefore, the soil characterisation is an important aspect of the assessment methodology. 


\section{Marine soils}

Critical to any foundation design are geotechnical considerations. Scour in the marine environment is a physical process related to the movement of seabed sediment by the flow of water away from a structure. The soil conditions are described by geotechnical parameters, therefore, scour is of a geotechnical nature as it relates to the reduction in ground level around a structure. Scour in uniform cohesionless soils is relatively well understood, but marine soils are rarely uniform in structure and can be multi-modal in their grading as well as exhibiting a varying amount of cohesion. Assessing the extent of the scouring in these real soils is far more complex and the methods available more limited.

The Earth Materials approach developed by Annandale (2006) defined a stream power parameter, $\mathrm{P}$, which is related to the rate of flow energy dissipation and an erodibility index, $\mathrm{K}$, which is related to the erodibility of the bed material. If $P<K$, no erosion takes place, but if $P>K$, erosion will occur. The Erodibility Index was defined for earth materials ranging from cohesionless granular soil through to massive hard rock, and including weathered rock. The approach allows for the physical properties of the soil to be considered and although the method does not directly take into account the chemical properties of the material, the mass strength number, MS, represents the relative influence of chemical bonding properties of the soil through the unconfined compressive strength.

Whether a site with clay layers will experience significant scour could be addressed using observations at existing structures, although this is not possible at a new site, through direct testing of erosion resistance performed in parallel with site investigation activities, by monitoring of scour around foundations once installed, or, for example, with application of the Earth Materials approach. Figure 1 shows an example application of the latter to a site in $30 \mathrm{~m}$ of water where clay underlies the whole site to depth. Over parts of the seabed there is a veneer of sand and gravel, generally to a depth of several decimetres, which is expected to scour due to the prevailing hydrodynamic conditions: Peak tidal currents in the water column vary between 0.7 and $1.7 \mathrm{~m} / \mathrm{s}$. Significant wave heights of up to $3.6 \mathrm{~m}$ were recorded, with a maximum wave height of $6.2 \mathrm{~m}$.

Figure 1 shows the variation with depth in the bed of the required stream power for erosion of an intact soil sample, with inputs derived directly from site investigation, and a remoulded sample. The curves of available stream power - in increasing order - relate to waves alone, currents alone and combined waves and currents showing the profile with depth if a scour hole was formed. Whilst in this particular case neither soil profile is predicted to scour given the available hydrodynamic conditions, the effect of remoulding reduces the soil strength significantly and thereby reduces the required stream power to erode the sediment by around $50 \%$ on average. This could have important implications for sites where the soils are likely to be significantly impacted on by installation of the foundation or other construction processes, for example, by dredging. In addition, other effects may occur, for example, the observations (2004) at Kentish Flats OWF (another predominantly clay site) indicate a depression forms around the installed; this was probably due to the combined effect of soil deformation during piling (a geotechnical issue) and scour (a hydraulic issue). Immediately post-construction these depressions were recorded to have depths of between $0.5 \mathrm{~m}$ and $2.0 \mathrm{~m}$. At the time of the survey in late 2007 these depressions had reduced, on average, by $0.6 \mathrm{~m}$. 


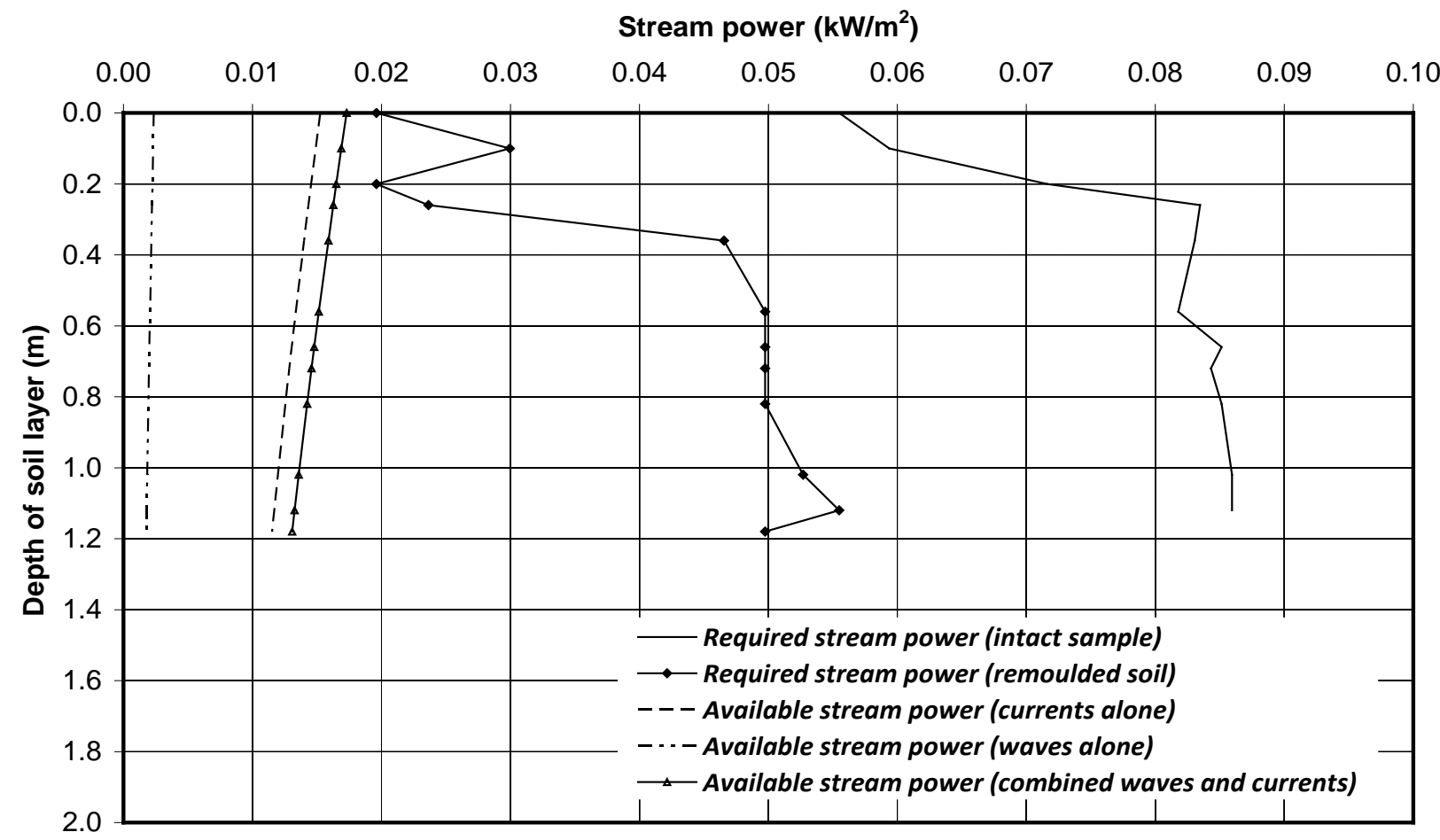

Figure 1: Plot showing the application of the Earth Materials to an offshore wind farm site with predominantly clay marine soils.

Additional impacts can arise from the operation of vessels during installation. Also observable in the monitoring surveys at Kentish Flats OWF were regular depressions caused by the jack-up vessel at the time of installation of the foundations.

\section{Time-scale of scour development}

Scour development under waves and currents around offshore structures is a time varying process. Whether a scour hole will continue to develop, remain at some equilibrium or fill in is a function of the hydrodynamic processes existing at any given time. Therefore, scour development is analogous to the growth and decay of, for example, seabed ripples. Under tidal flows the current reverses direction with the tidal state, consequently the scour development will take place in two directions. In addition, the magnitude of the current will vary through the period of the spring-neap tidal cycle.

Whitehouse (2006) highlighted the need to develop time-series methods for scour development and, in particular, using the results from such methods to investigate the probability of exceedance of scour around the foundations of offshore structures. This is a clear way of communicating the likelihood of scour occurring to particular depths from which risks to a particular project can be evaluated.

The time variation with respect to the period between installation of the foundation structure and the monitoring survey or surveys is important as there will be a general increase in scour depth to some equilibrium condition over a time-frame that will vary with site conditions. Under steady flow conditions the scour process will take some time to develop a scour hole and the development is often defined by a negative exponential growth curve (Whitehouse, 1998). 


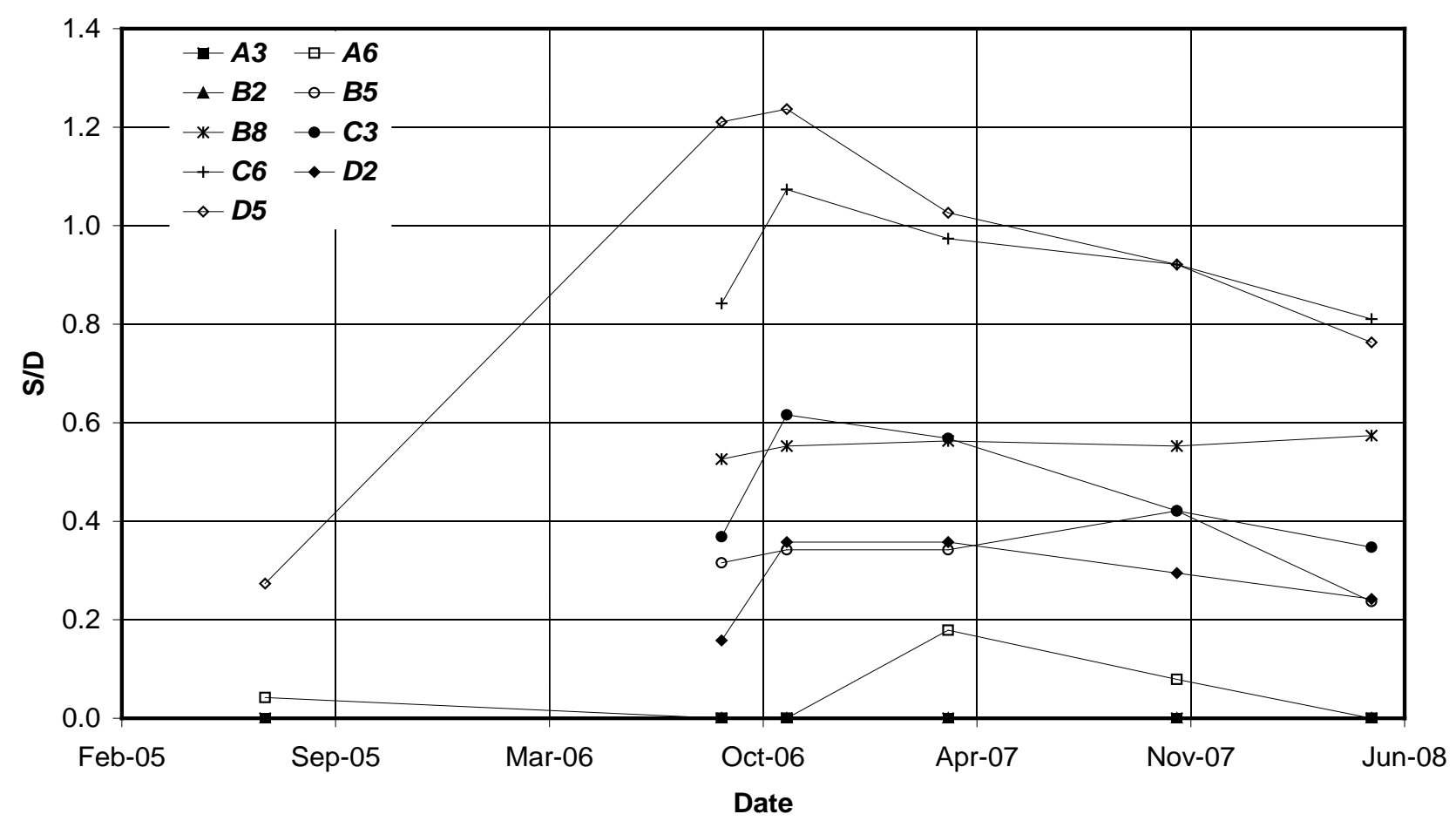

Figure 2: Variation of non-dimensional scour depth with time at Barrow Offshore Wind Farm

\section{Source: COWRIE, 2010}

The monitoring data for Barrow indicates a general growth in scour (Figure 2), although some deeper values have reduced more recently. Caution should be taken though in inferring a general reduction in scour depth with time, as this may just be a function of the prevailing conditions at the time of the survey rather than a general trend. A clearer picture of time evolution will be obtained from carrying out surveys at short time intervals after installation. Recent studies by Harris et al. (2010) suggest that the scour depth can vary significantly under combined current and wave conditions through time as demonstrated in Figure 3.

Harris et al. (2010) developed a semi-empirical based model to predict the time-evolution of scour. Figure 3 shows the results from the model at prototype scale using a pile diameter typical of that used in offshore wind farm construction ( $4 \mathrm{~m}$ diameter). At this site there was a moderate water depth ( $\approx 8 \mathrm{~m}$ mean sea level) and the results indicate a clear difference between the scour predicted including waves and not including them, and without waves there is more of a tidal effect evident in the scour depth evolution - the increased amplitude of oscillation relates to periods with larger tidal range and storm driven currents. The peak scour depth achieved under both scenarios is less than the maximum assumed equilibrium scour depth $(1.3 \mathrm{D} \approx$ $6.1 \mathrm{~m}$ ) and this indicates that at this location there is still a slight modification to the scour depth as a result of pile diameter to water depth ratio. There is also a significant difference between the initial rate of growth of scour with and without waves at this location with a much smaller initial rate of scour when waves are present. Validation of this kind of detailed modelling requires continuous time-series data of environmental conditions and scour depths at the foundation. 


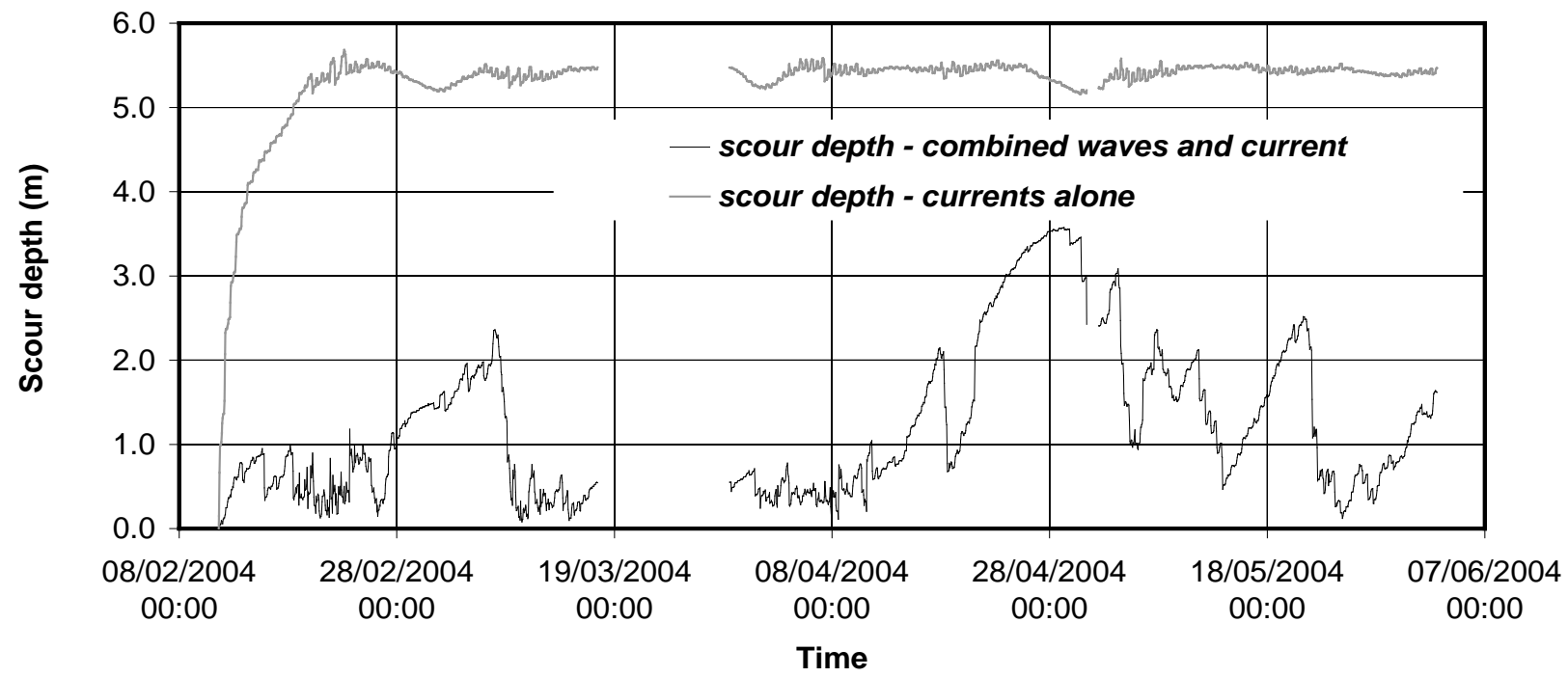

Figure 3: Modelled variation of foundation scour depth at a moderate water depth site

Source: Harris et al., 2010

\section{Evidence base}

It is considered good practice for scour evaluation that during the design process of the foundation an appropriate analysis is made for local scour arising from the influence of waves and currents taking account of spring and neap conditions and the influence of storm events, as well as the relative magnitude of waves and currents which will vary from location to location. In those locations where a strong reversing tidal flow exists it is advisable to evaluate the influence of that current pattern on scour development. The potential for scour interaction between adjacent foundations needs to be assessed. Finally, the influence of variations in bed level over the design life of the wind farm needs to be considered; this may arise from regional changes or local changes due to migration of seabed features such as banks, sandwaves or channels.

Studies carried out for Round 1 and 2 developments (DECC 2008; COWRIE 2010) have drawn together the sediment process monitoring work carried out on Round 1 and 2 offshore wind farm developments. They have reviewed the methods, data, results and impacts in order to identify lessons learnt and to provide relevant recommendations for future developments, whilst establishing an accessible evidence base. Results of this evaluation were presented by Whitehouse et al. (2008).

As part of these studies those aspects of sediment monitoring related to scouring around wind turbine foundations has been evaluated with the aim of examining scour patterns and lessons learnt at OWF sites in UK and European waters, where sufficient data is available. The evidence database on scour relates to monopile foundations in different sediment and hydrodynamic environments based on site surveys. The new insights from this data - based on work by the authors for COWRIE (2010) - are discussed with data presented in the standard parameters of the scour depth (S) non-dimensionalised with foundation diameter (D), and the water depth (h) also non-dimensionalised by foundation diameter.

Figure 4 presents scour data for built or under construction Round 1 and 2 wind farm sites as well as the Princess Amalia OWF in the Dutch Sector. The deepest scour recorded at Round 1 developments was at the Scroby Sands site $(S / D=1.38)$. In data from the Round 2 Robin Rigg site the foundation-averaged scour 
depth is up to $S / D=1.77$, with the majority of locations being less, in a similar range of water depths. The main clusters of data for Scroby Sands and Robin Rigg are deeper than the single value that was available for Arklow Bank. However, there is scatter in the S/D values for Robin Rigg such that the observations cover the range of existing predictive equations, i.e. 1.3D to 1.75D, and some foundations have lower periods of time between installation and survey which limits the scour development at the time the survey was taken. The data from Princess Amalia is in a cluster, with scour depths generally up to $S / D=0.81$, with one value deeper at $S / D=1.15$. The most recent data for Kentish Flats in a clay environment has values of $S / D$ up to 0.4. There is some evidence for fluctuations in scour with time at Kentish Flats, with two foundations apparently experiencing progressive scour depth increase with time. The data for Barrow shows low (no) scour in the clay sites. The newest data from North Hoyle (not plotted) shows evidence of little (no) scour around the foundations, which is in line with the results presented in Whitehouse et al. (2008).

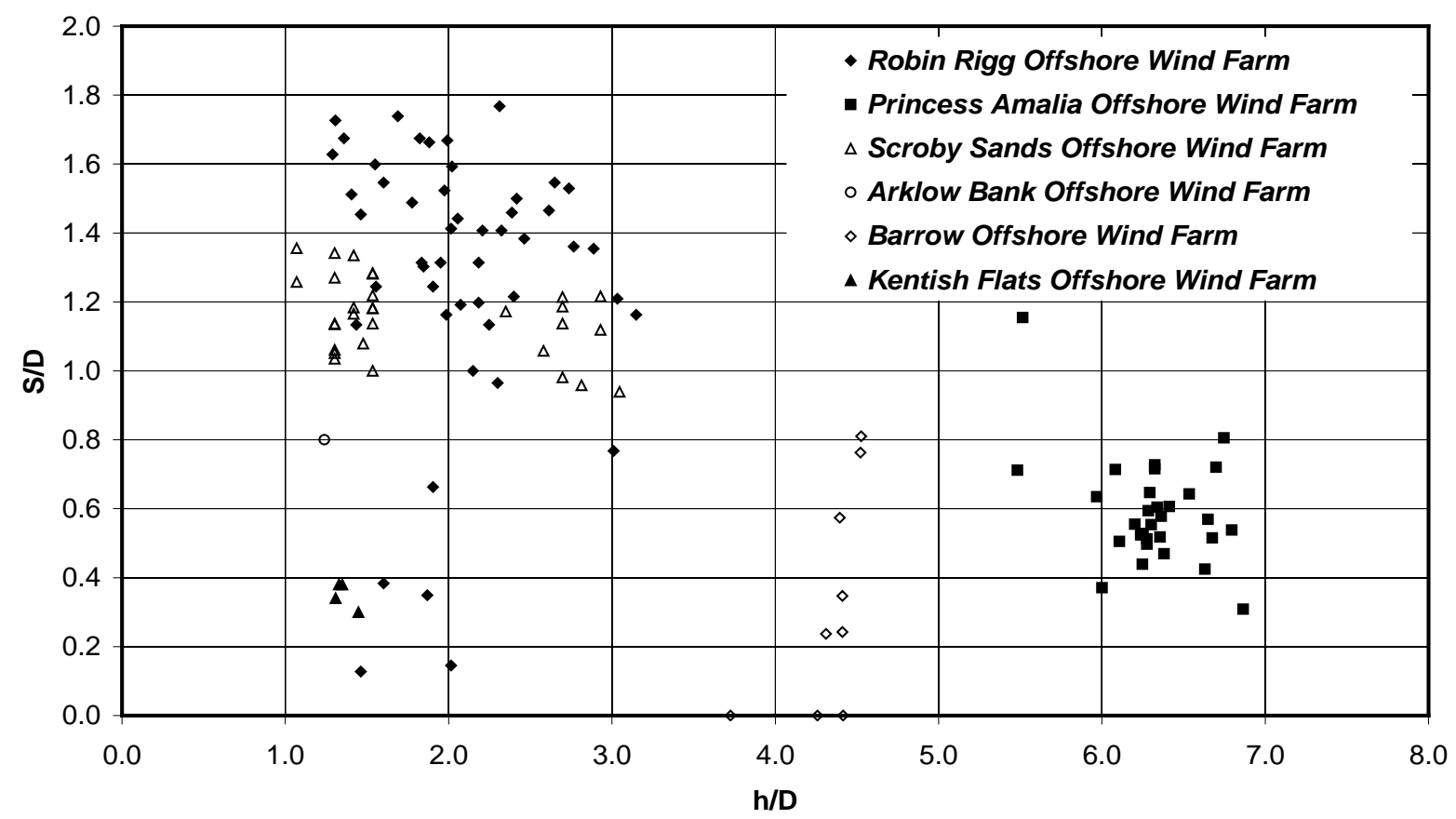

Figure 4: Non-dimensional plot of scour depth (S) data for offshore wind farms with no foundation scour protection in place (Note: $\mathrm{D}$ is monopile diameter and $\mathrm{h}$ is water depth to mean sea level)

\section{Source: COWRIE, 2010}

The maximum S/D values are broadly in agreement with the range suggested by Breusers and Raudkivi (1991). They suggested a value of $S / D=2.3$ when the flow velocity was four times the sediment threshold velocity. Below this condition they adopted a graphical approach to determining the multiplier based on experimental evidence. This is also in line with the approach given in Sumer and Fredsøe (2002) where the mean value of $S / D=1.3$ allows for a standard deviation term of 0.7 to be added, which would give an upper value of $S / D=2.0$.

As has been noted previously in DECC (2008) the data analysed supports the view that scour is a progressive process where the seabed sediment is naturally mobile, and there is an adequate thickness of that sediment for scouring to occur. Where the seabed is comprised of stiff clay, there is a superficial layer of sediment overlying clay or the wave and current conditions are not generally strong enough to cause the seabed sediment to be naturally mobile, the scour will be slower or limited. 


\section{Environmental data requirements}

In shallow water wave orbital velocities at the seabed are the critical wave parameter for estimating scour hazard. These are usually estimated from wave height and period using wave theory rather then being measured directly. A rigorous assessment of scour hazard would require some quantification of day to day wave activity in addition to extreme values. It would also be necessary to quantify how wave parameters vary with time and how long they persist above given thresholds, perhaps by characterising the typical frequency and duration of storms. A probabilistic approach might be appropriate where for example the cumulative frequency distributions of significant wave height are fitted to a well-known distribution such as the three-parameter Weibull distribution. In some locations it would also be necessary to quantify tidal and longer period variations in water level where these are large enough to affect the wave conditions.

In relatively deep water the influence of waves can (often) be neglected and scour hazard is likely to be controlled by currents. The depth at which wave action can be neglected will depend upon the wave climate at the site in question, so wave particle velocities at the seabed should be estimated for extreme wave conditions to determine potential scour hazard. In the simplest case, currents can be represented by an extreme value of current speed at $1 \mathrm{~m}$ above the seabed. These values are commonly derived using wellestablished techniques and an appropriate return period value should be selected according to the engineering application.

It is very important to know the surficial soil characteristics for a scour assessment, data starting from $1 \mathrm{~m}$ below the bed in a site investigation may not be representative of the surface sediment properties, but will be important for scour greater than $1 \mathrm{~m}$ deep. The influence of layering in the sandy and silty soils or the presence of a veneer of mobile sediment overlying, for example, stiff clay need to be taken into account in the assessment. Construction effects on soil properties must also be considered if these are expected to change the soil properties related to the foundation.

\section{Future research}

As well as maintaining the existing evidence base as new data becomes available, there are four distinct but related areas in which further research will lead to benefits in understanding and predicting scour response. The first relates to the time variation in scour at sandy sites; the second to scour potential and scour development with time in heteregeneous soils (gravel-sand-silt-clay mixtures); the third relates to complex foundation structures (gravity base, jacket and multi-leg foundations), and the fourth relates to the optimisation of scour protection performance for monopile and complex foundation structures:

1. There is an issue of time development of scour holes in a varying wave and current environment and this can have implications for foundations, cabling and the placement of scour protection. Detailed time series measurements of scour and environmental conditions are required to validate (or improve) existing models.

2. There is uncertainty of scouring around foundations in heterogeneous soils and, currently, there is no specific guidance as to how best to assess scour potential in such situations. The Earth Materials approach (Annandale, 2006) shows promise and there is a requirement for a review of available methods in light of actual environmental conditions experienced, site data on soils, and observed scour development offshore. Once this review has been completed recommendations can be made for the most appropriate approaches to adopt. 
3. There is little evidence as to the performance of installed scour protection around existing OWF sites (e.g. other than DECC, 2008). The scour protection that has been placed appears to be effective in preventing bed lowering adjacent to the foundations, although filter layers appear to be necessary to prevent settlement of rock armour layers. Where material has been placed in the scour hole, and the top level is above the level of the surrounding seabed level, it is evident that the mound of protection material has produced a secondary scour response in mobile sediment environments. Further analysis of measurements of scour protection level and profile would be useful, combined with visual information to show how the surface of the scour protection material varies with time (e.g. armouring, infill with fines).

This will inform the production of guidance on the role of placement methodology in the evolution of the scour protection and the interaction of the protection with the surrounding seabed. In the longer term data will be required to evaluate the scour protection performance under the influence of regional changes in bed level (e.g. on sandbanks, sandwaves and due to channel movement).

4. For foundation structures other than monopiles it is necessary to use a combination of approaches to estimate likely scour around the foundation. The general suitability of these approaches acts as an uncertainty in the design process. Further, the representation of more complex foundation types in the typical shallow water coastal modelling systems that are used in the environment assessments is a large uncertainty. This uncertainty can be reduced through a programme of detailed laboratory experiments combined with numerical modelling. This approach is of particular interest when determining how to deal with other non standard foundation shapes, such as those encountered with seabed mounted wave energy devices.

\section{Acknowledgements}

The research was made possible through the support of offshore wind farm developers in providing data to inform the COWRIE and DECC work. With respect to results included from the COWRIE work specific acknowledgement is made to E.ON, Climate \& Renewables UK for allowing the use of scour monitoring data from the Robin Rigg Offshore Wind Farm, and Van Oord Dredging and Marine Contractors BV for allowing the use of scour monitoring data from the Princess Amalia Wind Farm. The views, results and conclusions are those of the authors and not necessarily those of the funders or those providing the data. Support for additional research and preparation of the paper came from the company research programme of HR Wallingford.

\section{References}

Annandale, G.W. (2006). Scour Technology. Mechanics and Engineering Practice. McGraw-Hill.

Breusers, H.N.C. and Raudkivi, A.J. (1991). Scouring. IAHR Hydraulic Structures Design Manual, 2, A. A. Balkema, Rotterdam, vii + 143 p.

Byrne, B. W. and Houlsby, G.T. (2003). Foundations for offshore wind turbines. Phil. Trans. R. Soc. Lond. A, 361, 2909-2930.

COWRIE (2010). A Further Review of Sediment Monitoring Data. Final Report prepared by ABPmer Ltd, HR Wallingford Ltd and CEFAS for the Research Advisory Group, Project Ref. ScourSed-09, March, 115 p.

DECC (2008). Dynamics of scour pits and scour protection - Synthesis report and recommendations (Milestones 2 and 3). Final Report prepared by HR Wallingford Ltd, ABPmer Ltd and CEFAS for the 
Research Advisory Group, Department of Energy and Climate Change (DECC) and Department for Environment, Food and Rural Affairs (Defra).

Harris, J.M., Whitehouse, R.J.S. and Benson, T. (2010). The time evolution of scour around offshore structures. Proceedings of the Institution of Civil Engineers, Maritime Engineering, 163, March, Issue MA1, 3 -17 .

Sumer, B.M. and Fredsøe, J. (2002). The Mechanics of Scour in the Marine Environment. Advanced Series on Ocean Engng., Vol. 17, World Scientific, Singapore. xiii + 536 p.

Whitehouse, R.J.S (1998). Scour at marine structures: A manual for practical applications. Thomas Telford, London, $198 \mathrm{p}$.

Whitehouse, R. (2006). Scour at coastal structures (Invited lecture). Proceedings Third International Conference on Scour and Erosion, November 1-3, pp. 52-59, (c) CURNET, Gouda, The Netherlands [CDROM].

Whitehouse, R., Harris, J., Sutherland, J. and Rees, J. (2008). An assessment of field data for scour at offshore wind turbine foundations. Proceedings Fourth International Conference on Scour and Erosion, Tokyo, Japan, Paper B-13, 329-335. 